\title{
DIABETIC ALBINO RATS; BLOOD GLUCOSE, SUPEROXIDE DISMUTASE AND GLUTATHIONE PEROXIDASE IN CINNAMON CASSIA TREATED
}

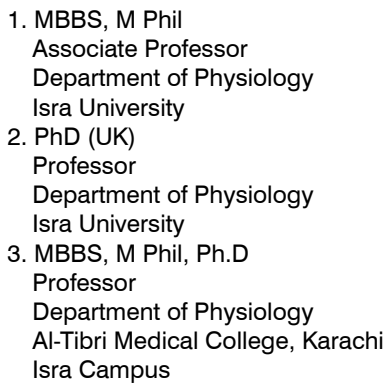

Correspondence Address: Dr. Navaid Kazi Associate Professor

Department of Physiology

Isra University

qaisernaqvipk@yahoo.com

Article received on:

28/12/2015

Accepted for publication:

25/02/2016

Received after proof reading: 04/05/2016

\section{Dr. Navaid Kazi' ${ }^{1}$, Dr. Din Muhammad Shaikh², Dr. Muhammad Ahmed Azmi ${ }^{3}$}

\begin{abstract}
Objectives: The present study evaluated the blood glucose, superoxide dismutase (SOD) and glutathione peroxidase (GPX) in Cinnamon cassia bark extract (CCBE) treated alloxan-induced diabetic albino rats. Study Design: Experimental study. Setting: Animal house of Al-Tibri Medical College, Karachi was selected for conducting the present study. Period: January 2014 to December 2014. Methodology: A sample of twenty rats was randomly divided into 4 groups. Rats were grouped as A1 $(n=5)$ - Negative control, A2 $(n=5)$ - Positive controls (alloxan treated rats), and experimental groups B1 $(n=5)$ and B2 $(n=5)$ included diabetic rats which received 0.3 grams and 0.6 grams of CCBE respectively. Intraperitoneal alloxan (120 mg $/ \mathrm{kg}$ in $0.5 \mathrm{ml}$ dissolved in acetate buffer) was used for induction of diabetes. C. cassia bark extract was prepared under standard protocol. Blood glucose (glucose oxidase method), SOD and GPX (Elisa kit) were detected from blood samples after 30 days. Data was analyzed on SPSS. Data was analyzed by one- way ANOVA and post-Hoc was used for group comparisons. Data was analyzed at $95 \% \mathrm{Cl}(\mathrm{p} \leq 0.05)$. Result: Blood glucose, SOD and GPX showed statistically significant differences $(p<0.036)$. CCBE treated rats showed low glucose levels and elevated SOD and GPX enzyme activity $(p<0.05)$.
\end{abstract}

Key words: $\quad$ Cinnamon cassia Superoxide dismutase Glutathione peroxidase Blood glucose Rats

Article Citation: Kazi N, Shaikh DM, Azmi MA. Diabetic albino rats; blood glucose, superoxide dismutase and glutathione peroxidase in cinnamon cassia treated. Professional Med J 2016;23(5):603-607. DOI: 10.17957/TPMJ/16.3226

\section{INTRODUCTION}

Botanically, the Cinnamon cassia (C. cassia) belongs to the plant family called Cinnamon. The Cinnamon includes hundreds of species which differ from each other. Species of Cinnamon are termed according to their geographical location and local names in different geographical regions; such as "Java cinnamon" which is inherent to Java. Other species are named as "Padang cassia", C aromaticum, C. cassia blume, C. tora, C. burmanii, C. obtusifolia and C. loureininees. ${ }^{1,2}$ In Indo- Pak, the cassia is publicly known as the Dalchini, the term in the local name used by the aborigines. C cassia is serrated plant herb. Cassia and Cinnamon differ in their plant origin and composition. Both alos differ for their nutrient content and nutritional values and health benefits. Some of Cassia species contain coumarin anti-coagulant in sufficient quantities to cause coumarin toxicity. Different species of Cassia and Cinnamon also differ in their biological activity.
Ceylon cinnamon and C. zeylanicum are famous species for their biological activity and are widely studied. ${ }^{1-2}$

Cinnamon is publicly known and is widely used as food spice because of its aroma and taste enhance due to its typical fragrance. Hence it is widely used as food additive. Cinnamon is used in industry for liquor preparation on large scales. Cinnamon was exported for liquor preparation during the British rule. One drawback of some species of Cinnamon is the presence of anticoagulant substance called coumarin which is reported to cause toxicity. Another species of Cinnamon which is grown in Ceylon (Sri Lank), called Ceylon cinnamon, is reported to contain least quantity of coumarin; hence it is regarded as an ideal spice due to safety and no toxicity. Coumarin is reported to be present in the bark of the plant, particularly in the $\mathrm{C}$. cassia. The Ceylon cinnamon contains no coumarin; instead it is 
rich in eugenol and benzyl benzoate. Cinnamon composition and coumarin content depends upon various factors such as the climate, environmental conditions, geographical area, and particularly the species. . $^{3-5}$

Since time immemorial, the $\mathrm{C}$ cassia is used as food spice by the people of indigenous areas. Use of C cassia may be traced back to 5000 years ago, when it was used increasing appetite, prevent diarrhea, nausea and flatulence, blood glucose regulator and for different problems of digestion. ${ }^{6-7}$

A previous study reported the $\mathrm{C}$ cassia regulates the blood glucose favorably in diabetic patients. Glycemic status was improved when C cassia was used concomitantly with $\mathrm{C}$ cassia. ${ }^{8}$ However; the active therapeutic ingredient which regulates the blood glucose remains an enigma and needs to be explored. One such chemical ingredient reported includes the "Methyl-hydroxyl chalcone polymer" (MHCP). The MHCP's glucose lowering potential is attributed to its "mimicry" at molecular level for cell membrane receptors including those of insulin. ${ }^{10,11}$ A previous in vitro study demonstrated that the MHCP functions at the level of insulin receptor in target cells thereby ameliorate the blood glucose. ${ }^{12}$ Activity of MHCP on insulin receptor was demonstrated in 3T3-L1 adipocytes in rat model. ${ }^{13}$ Other studies claimed the Polyphenols were responsible for regulating the blood glucose, mainly the "polyphenol A". ${ }^{13-}$ ${ }^{15}$ The present experimental study evaluated the blood glucose, SOD and GPX in Cinnamon cassia bark extract (CCBE) treated alloxan-induced diabetic albino rats.

\section{MATERIAL AND METHODS}

Animal house of Al-Tibri Medical College, Karachi was selected for conducting the present experimental study. The study was conducted from January 2014 to December 2014. Blood samples were analyzed at the Diagnostic
Laboratory of LUMHS, Hyderabad. Materials for present experimental study were 20 rats, selected by simple random sampling and divided into 4 groups. Inclusion and exclusion criteria were observed. Animals were housed in stainless steel cages according to guidelines for animal handling. Chow and free access to water was ensured. 12 hour light and dark cycles and temperature \& humidity were maintained strictly at optimum. Rats were grouped as A1 $(n=5)$ - Negative control, A2 $(n=5)$ - Positive controls (alloxan treated rats), and experimental groups B1 $(n=5)$ and B2 $(n=5)$ included diabetic rats and were treated with 0.3 grams and 0.6 grams of CCBE respectively. Intraperitoneal alloxan $(120 \mathrm{mg} / \mathrm{kg}$ in $0.5 \mathrm{ml}$ dissolved in acetate buffer) was used for induction of diabetes. Diabetic rat was defined as blood glucose $>250 \mathrm{mg} / \mathrm{dl}$ on 3 consecutive days. C. cassia bark extract was prepared under standard protocol. Blood glucose (glucose oxidase method) on Hitachi Chemistry analyzer, SOD and GPX (Randox Elisa kit) were detected from blood samples (obtained from tail of rats) after 30 days. Data was analyzed on SPSS. Data was analyzed by one- way ANOVA and post-Hoc (Fischer LSD) was used for group comparisons. Data was analyzed at 95\% Cl $(P \leq 0.05)$.

\section{RESULTS}

Table-l. Shows the blood glucose levels, SOD and GPX activity in controls, positive controls and experimental rats. Blood glucose, SOD and GPX showed statistically significant differences $(p<0.036)$. CCBE treated rats showed low blood glucose levels and elevated SOD and GPX enzyme activity $(p<0.05)$. The findings of present study shows the CCBE extract regulates blood glucose and increases the blood SOD and GPX activity. 0.6 grams CCBE treated rats showed more significant improvement in blood glucose, SOD and GPX. Bar Figures 1-6 show the blood glucose, SOD and GPX in rats of controls, positive controls and experimental groups. 


\begin{tabular}{|l|c|c|c|c|}
\hline & Glucose $(\mathbf{m g} / \mathbf{d l})$ & SOD $(\mathbf{U} / \mathbf{m l})$ & GPX (U/ml) & P-value \\
\hline Group A1 & $122.0 \pm 9.33$ & $196.0 \pm 18.38$ & $10832.2 \pm 943.9$ & 0.001 \\
\hline Group A2 & $420.1 \pm 66.92$ & $71.4 \pm 10.59$ & $2745.1 \pm 1367.4$ & 0.001 \\
\hline Group B1 & $359.0 \pm 64.48$ & $126.2 \pm 14.73$ & $7651.0 \pm 3133.1$ & 0.036 \\
\hline Group B2 & $251.4 \pm 70.24$ & $178.6 \pm 97.02$ & $13628.4 \pm 1358.1$ & 0.001 \\
\hline
\end{tabular}

Table-I. Blood Glucose, Superoxide Dismutase and Glutathione Peroxidase in different rat groups $(\mathrm{n}=20)$

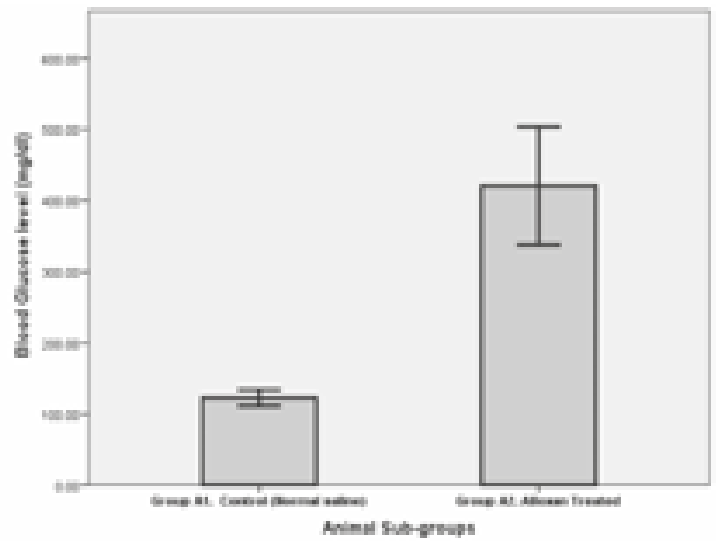

Figure-1. Blood glucose in controls and positive control rats

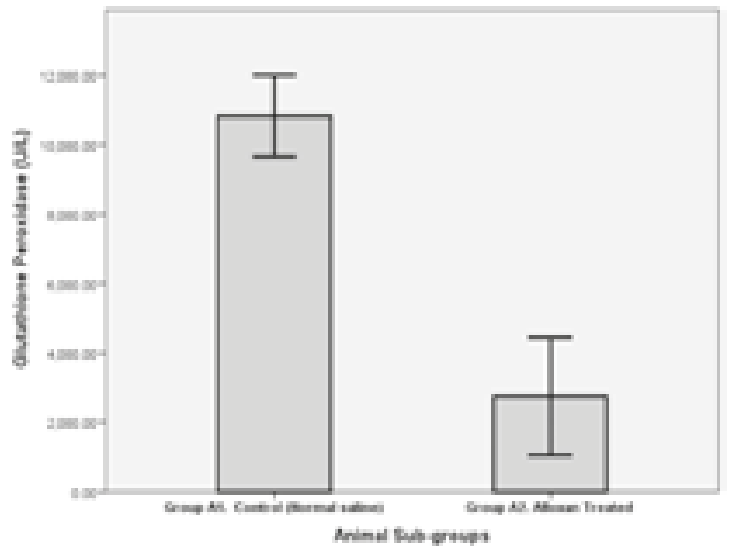

Figure-3. Glutathione peroxidase in controls and positive control rats

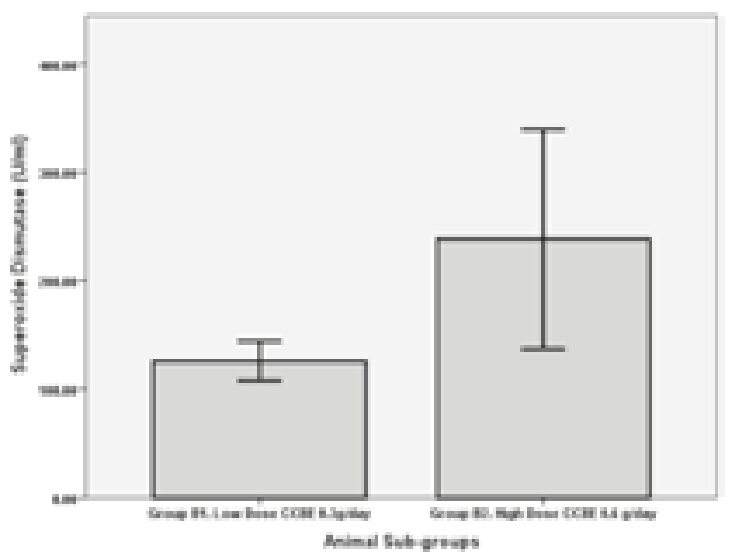

Figure-5. Superoxide dismutase in Cinnamon extract treated diabetic rats

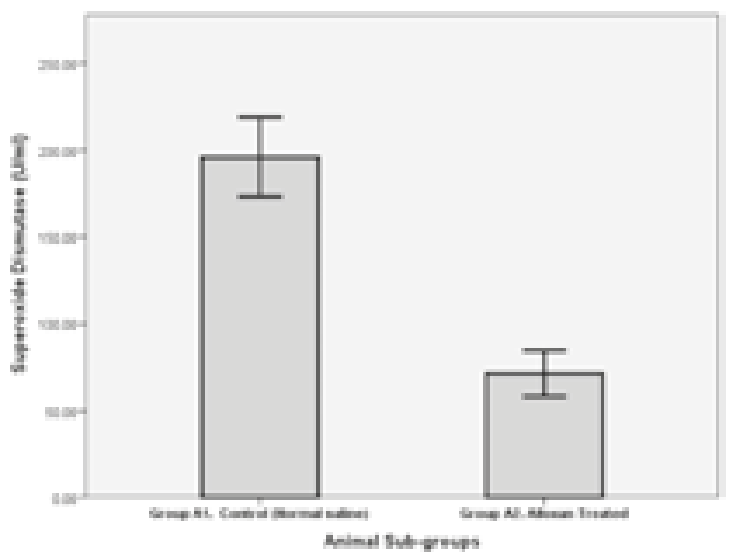

Figure-2. Superoxide dismutase in controls and positive control rats

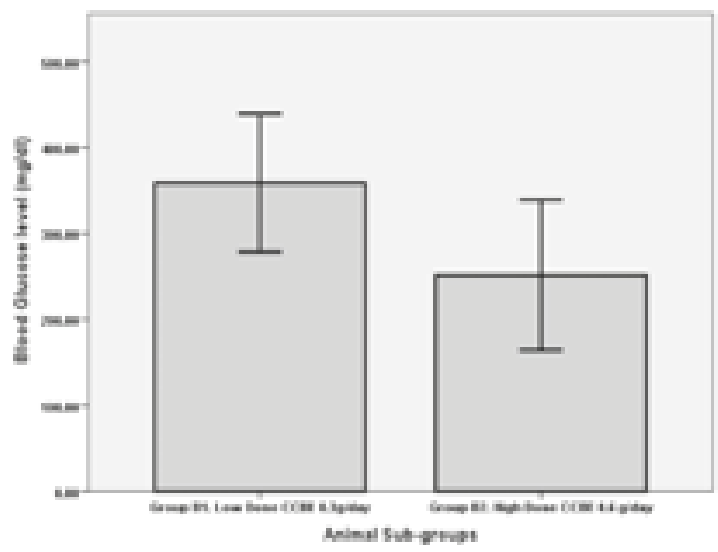

Figure-4. Blood glucose in Cinnamon extract treated diabetic rats

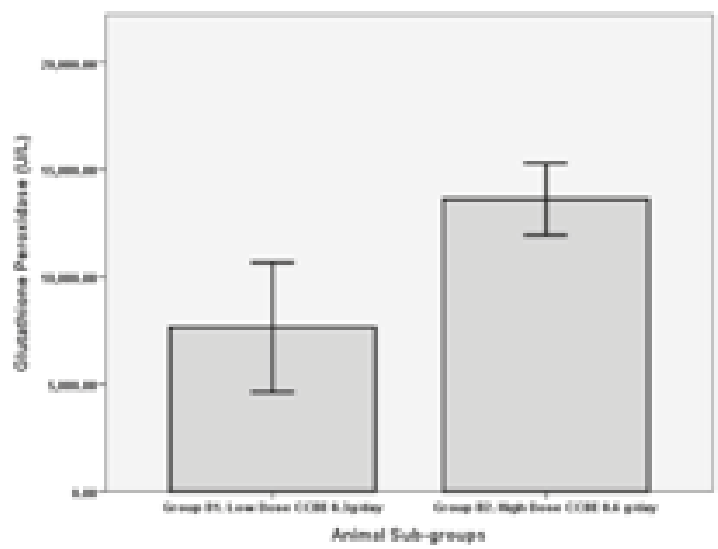

Figure-6. Glutathione peroxidase in Cinnamon extract treated diabetic rats 


\section{DISCUSSION}

The present study evaluated the blood glucose, superoxide dismutase (SOD) and glutathione peroxidase (GPX) in Cinnamon cassia bark extract (CCBE) treated alloxan-induced diabetic albino rats. To the best of our knowledge and a search of literature, it shows the present is the first study conducted at Al-Tibri Medical College and being reported. The blood glucose, SOD and GPX were improved by CCBE in diabetic rats at day 30 of alloxan induced diabetes. The findings of present study are supported by previous studies cited as. ${ }^{9-11}$ Above studies reported that the $\mathrm{C}$ cassia extract lowers blood glucose which is a consistent finding, however, the SOD and GPX is typical incomparable finding of present study as both enzymes were not analyzed. A previous study reported the "Methyl-hydroxyl chalcone polymer" (MHCP) ingredient was responsible for glucose lowering due to its mimicry to insulin receptors at molecular level. ${ }^{10,11}$ Another previous in vitro experimental study demonstrated that the MHCP functions at the level of insulin receptor in target cells thereby ameliorate the blood glucose. $^{12}$ The finding of amelioration of blood glucose is a consistent finding with our present study. Anderson et al reported that the MHCP acts on insulin receptor as they proved it on the 3T3-L1 adipocytes in experimental rats. ${ }^{13}$ Other studies claimed the Polyphenols were responsible for regulating the blood glucose, mainly the "polyphenol A". ${ }^{13-15}$ Whatever, the underlying mechanism, it remains to be elucidated further. However, the finding of blood glucose lowering potential is a comparable to present study. MHCP as the active ingredient responsible for glucose lowering $^{12}$ is still debatable.

Kamble et $\mathrm{al}^{16}$ evaluated the glucose lowering effect of $C$ cassia extract and has reported similar observations consistent to our present study. Kamble et $\mathrm{al}^{16}$ compared the aqueous extract of C. cassia with glibenclamide and Metformin in diabetic rats. Kamble et $\mathrm{al}^{16}$ concluded that the extract of $\mathrm{C}$. cassia was as effective as glibenclamide and Metformin.

Another study ${ }^{17}$ evaluated the effects of $C$ cassia extract in fructose induced diabetic rats with insulin resistance. This previous study concluded that the $\mathrm{C}$ cassia extract improves blood glucose and overcomes insulin resistance. ${ }^{17}$ The present study shows comparable observations as regards the blood glucose lowering.

A recent study by Kannapan et $\mathrm{al}^{18}$ evaluated the expression of hexokinase enzyme in target cells. Hexokinase is important enzymes of glucose metabolism. It was proved by above study that the $\mathrm{C}$ cassia extract increased the hexokinase expression many times. Glycogen stores of liver and muscle were also increased. It was concluded that the $\mathrm{C}$ cassia extract improves glucose metabolism as indicated by increased hexokinase activity in target, and increased glucose entry as revealed by increased glycogen in liver and muscle. The finding of glucose lowering effect of $\mathrm{C}$ cassia is consistent to our present study but the underlying mechanism which was evaluated in above study. ${ }^{18}$ Another previous study reported an improvement in blood glucose levels by $C$ cassia extract in a diabetic $\mathrm{db} / \mathrm{db}$ mice models. ${ }^{19}$

Babu et $\mathrm{al}^{20}$ has also reported similar effects of Cinnamaldehyde (active ingredient of $\mathrm{C}$ cassia) in streptozocin induced diabetic Wistar rats. Babu et $\mathrm{al}^{20}$ also reported beneficial effects on the triglycerides, cholesterol and activity $\alpha$-glycosidase enzyme in rats. Babu et al ${ }^{20}$ concluded hypoglycemic and hypolipidemic effects of Cinnamaldehyde which is an active ingredient of $\mathrm{C}$ cassia. The present study reports beneficial effects of $\mathrm{C}$ cassia extract on the blood glucose and increased expression of SOD and GPX enzyme activity in alloxan induced rats. Further studies may be conducted and $C$ cassia extract may be used as an aid on therapy to drugs in type 2 diabetic subjects.

\section{CONCLUSION}

The present experimental study reports $C$ cassia bark extract has potential of glucose homeostasis. It increases the anti-oxidant enzymes; the SOD and GPX, thus may protect against free radicals mediated injury in diabetics patients.

Copyright @ 25 Feb, 2016. 


\section{REFERENCES}

1. European Medicine Agency. Science Medicines Health: Assessment report on Cinnamomumverum J. S. Presl, cortex and corticisaetheroleums. 2011.

2. Jia Q, Liu X, Wu X, Wang X, Hu Y, Li C. Cinnamomum cassia. Phytomedicine. 2008; 16: 744-50.

3. Hoehn AN, Stockert AL. The Effects of Cinnamomum Cassia on Blood Glucose Values are Greater than those of Dietary Changes Alone. Nutrition and Metabolic Insights.2012; 5: 77-83.

4. Cheng TC, Cheng WL, Hsu JC, Shih Y, Chou ST. Chemical composition and tyrosinase inhibitory activity of Cinnamomum cassia essential oil. Botanical Studies 2013; 54: 10.

5. Blevins SM, Leyva MJ, Brown J, Wright J, Scofield RH, Astone CE. Effect of cinnamon on glucose and lipid levels in non-insulin-dependent type 2 diabetics. Diabetes Care 2007; 30 (9): 2236-7.

6. Meletis CD. Complete Guide to Safe Herbs. New York: DK Publishing. 2002.

7. Hoehn AN, Stockert AL. The Effects of Cinnamomum Cassia on Blood Glucose Values are Greater than those of Dietary Changes Alone. Nutrition and Metabolic Insights 2012; 5: 77-83.

8. Baker WL, Kluger J, Gutierrez-Williams G, Coleman Cl, White CM. (2008) Effect of cinnamon on glucose control and lipid parameters. Diabetes Care 2008; 31(1):41-3.

9. Davis PA, Yokoyama W. Cinnamon intake lowers fasting blood glucose: meta-analysis. J Med Food 2011; 14(9):884-9.

10. Khan A, Safdar A, Khan MMA, Khatak KN, Anderson RA. Cinnamon Improves Glucose and Lipids of People with Type 2 Diabetes. Diabetes Care 2003; 26:3215-8.

11. Kirkham S, Akilen $R$, Sharma S, Tsiami A. The potential of cinnamon to reduce blood glucose levels in patients with type 2 diabetes and insulin resistance.
Diabetes ObesMetab 2009; 11(12):1100-13.

12. Jarvill-Taylor KJ, Anderson RA, Graves DJ. A hydroxychalcone derived from cinnamon functions as a mimetic for insulin in 3T3-L1 adipocytes. J Am CollNutr 2001; 20(4):327-36.

13. Anderson RA. Chromium and polyphenols from cinnamon improve insulin sensitivity. $P$ NutrSoc 2008; 67(1):48-53.

14. Curtis PJ, Sampson M, Potter J, Dhatariya K, Karoon PA, Cassidy A. Chronic ingestion of flavan-3-ols and isoflavones improves insulin sensitivity and lipoprotein status and attenuates estimated 10-year CVD risk in medicated postmenopausal women with type 2 diabetes A 1-year, double-blind, randomized, controlled trial. Diabetes Care 2012; 35(2):226-32.

15. Jia $Q$, Liu $X, W u \quad X$. Hypoglycemic activity of a polyphenolic oligomer-rich extract of Cinnamomumparthenoxylon bark in normal and streptozotocin-induced diabetic rats. Phytomedicine 2009; 16(8):744-50.

16. Kamble S, Rambhimaiah S. Antidiabetic activity of aqueous extract of Cinnamomum cassia in alloxan induced diabetic rats. Biomed Pharmacol J 2013; 6 (1): 83-8.

17. Qin B, Panickar KS, Anderson RA. Cinnamon: Potential role in the prevention of insulin resistance, metabolic syndrome and type 2 Diabetes. J. Diabetes Sci. Technol 2010; 4 (3): 685-93.

18. Kannappan $S$, Jayaraman $T$, Rajasekar P, Ravichandran T, Anuradha CV. Cinnamomum cassia improves blood glucose and insulin release. Singapore Med J 2006; 47: 858-63.

19. Kim SH, Hyun SH, Choung SY. Cinnamomum cassia. J Ethnopharmacol2006; 104: 119-23.

20. Babu PS, Prabuseenivasan S, Ignacimuthu S. Cinnamomum cassia regulates blood glucose levels. Phytomedicine. 2007; 14: 15-22.

\section{AUTHORSHIP AND CONTRIBUTION DECLARATION}

\begin{tabular}{|c|l|l|l|}
\hline Sr. \# & \multicolumn{1}{|c|}{ Author-s Full Name } & \multicolumn{1}{|c|}{ Contribution to the paper } & Author=s Signature \\
\hline 1 & Dr. Navaid Kazi & 1st Author \\
\hline 2 & Dr. Din Muhammad Shaikh & 2nd Author \\
3 & Dr. Muhammad Ahmed Azmi & 3rd Author & \\
\hline
\end{tabular}

